\title{
Genomic identity of pyelonephritogenic Escherichia coli isolated from blood, urine and faeces of children with urosepsis
}

\author{
MARIA E. JANTUNEN*†, H. SAXÉN*, SUSANNA LUKINMAA $\dagger$, MARJA ALA-HOUHALA $\ddagger$ and \\ ANJA SIITONEN† \\ * Hospital for Children and Adolescents, University of Helsinki, PO Box 280, FIN-00290 Helsinki, †Laboratory \\ of Enteric Pathogens, National Public Health Institute (KTL), Mannerheimintie 166, FIN-00280 Helsinki and \\ †Department of Pediatrics, Tampere University Hospital, PO Box 2000, FIN-33521 Tampere, Finland
}

\begin{abstract}
Chromosomal genotypes of Escherichia coli isolates from blood, urine and faeces of infants with urosepsis were studied to find possible clonality of the isolates. The isolates were analysed by PCR for class I, II and III alleles of the pyelonephritis-associated adhesin gene papG. The macrorestriction profiles of the papG-positive isolates were analysed by pulsed-field gel electrophoresis and their $O$ serogroups were determined. Genetically identical $E$. coli isolates from the blood, urine and faeces of the same infant were found in 8 of 10 infants. This finding confirmed the results of previous phenotypic studies that the reservoir of pyelonephritogenic $E$. coli is indeed the colon.
\end{abstract}

\section{Introduction}

The reservoir of pyelonephritogenic Escherichia coli is believed to be the colon. This hypothesis is based on old findings $[1,2]$, which showed that $E$. coli isolated from the urine of a patient suffering from a urinary tract infection (UTI) belonged to the same O serogroup as a strain isolated simultaneously from the faeces of the same patient. It was reported later that these urinary and faecal isolates expressed similar P-fimbrial adhesins [3], which are the major virulence factors of uropathogenic $E$. coli. The production of these adhesins is encoded by pap $G$ genes [4]. This study investigated whether $E$. coli isolates from blood, urine and faeces of the same child with urosepsis were genetically identical, as no such study analysing isolates from these three sources with new molecular methods has yet been published.

\section{Patients and methods}

The bacterial strains and background data originated in a prospective, open, multicentre study of 180 children with acute pyelonephritis (PN) [5]. Children (1-24 months old) with PN were studied. Informed consent

Received 6 Nov. 2000; accepted 3 Jan. 2001.

Corresponding author: Dr M. E. Jantunen (e-mail: maria. jantunen@hus.fi). was obtained from the parent(s) or guardians at entry. The study protocol was approved by the institutional review board and the ethics committee of each participating unit. PN was defined by a positive urine culture (i.e., growth of $\geqslant 10^{5} \mathrm{cfu} / \mathrm{ml}$ in two consecutive sterile-bag specimens or any growth in a suprapubic bladder aspirate) and two out of three of the following criteria: C-reactive protein $>25 \mathrm{mg} / \mathrm{L}$, fever $\geqslant 38.0^{\circ} \mathrm{C}$, or pyuria (leucocyte count $>10 / \mathrm{mm}^{3}$ ). Patients who had received antibiotic treatment within the preceding 2 weeks, and those with known congenital anomalies of the urinary tract or central nervous system-associated anomalies were excluded.

Blood cultures (148 of $180 ; 82 \%$ ) were taken if indicated clinically. Both blood and urine samples were cultured by standard methods [6]. To collect faecal samples in a standardised manner, rectal swabs were taken. Chromogenic agar (Chromogenic E. coli/Coliform Medium; Oxoid) plates that selectively allowed the growth and preliminary differentiation of E. coli were inoculated with the swabs. Blood, urinary and faecal E. coli isolates, as well as faecal primary cultures, were analysed by PCR for class I, II and III alleles of the pyelonephritis-associated adhesin gene papG [7]. To ensure the detection of E. coli carrying pap $G$ in faecal samples, growth from the first streaking area of the faecal culture and five separate $E$. coli colonies on the fourth streaking area of the culture plate were tested directly for papG. Of the papGpositive faecal cultures, the specific papG-positive 
colonies were subsequently isolated and their identification was confirmed by standard methods [6]. The macrorestriction profiles of the papG-positive blood and urinary isolates and one faecal isolate were analysed further by pulsed-field gel electrophoresis (PFGE) after $X b a \mathrm{I}$ restriction of chromosomal DNA [8]. The isolates were $\mathrm{O}$ serogrouped by standard methods [9].

\section{Results and discussion}

Blood cultures yielded bacteria in $12(8 \%)$ of 148 cases; E. coli was grown from 11 and Enterobacter cloacae from one. Staphylococcus epidermidis grew in two other blood cultures but they were considered to be skin contaminants and non-significant findings. Ten children with E. coli isolates present in the blood and urine also had faecal isolates available for further characterisation; one child had only one blood isolate available and, therefore, was excluded from the analysis. The serotype of all isolates from all three sources was identical for a given child; however, in two children all the isolates were $\mathrm{O}$ non-typable. The genomic fingerprinting by PCR for papG and PFGE revealed that all three isolates from all three sources from each individual child were genotypically identical in eight children (Table 1, Fig. 1). In faecal samples of eight children at least three of five separate colonies tested from the fourth streaking area of the culture plate were positive for papG. This finding suggests that $E$. coli with pap $G$ genes can be considered to represent major facultative flora of the intestine in these children. One child (no. 6) had a PCR papG-positive E. coli only from the growth taken from the first streaking area and in another child (no. 7) no papG-positive E. coli could be detected in faeces despite the highly sensitive PCR detection method used. This failure to detect pap $G$-positive $E$. coli from the gut of one child may be because, in this child, papG-positive E. coli represented a minority population in the stools.

In the present study, the percentage of the positive blood cultures was low ( $8 \%$ ) but similar to an earlier report (9\%) [10] and higher than another (4\%) [11]. In spite of the multicentre design of the study carried out in five paediatric hospitals, it was successful in a

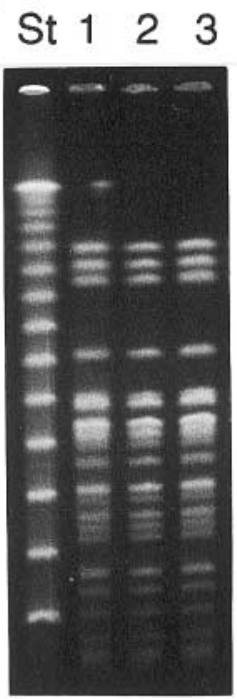

b

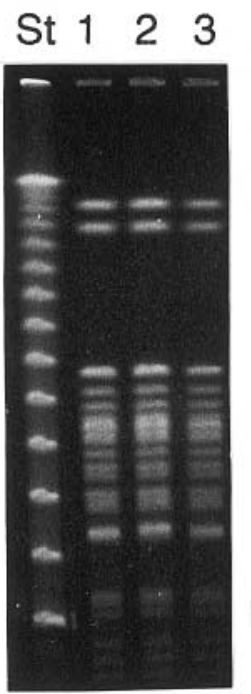

Fig. 1. PFGE banding patterns of (1) blood, (2) urinary and (3) faecal isolates from (a) child no. 9 and (b) child no.10 with E. coli urosepsis. St, molecular size markers.

collecting urine and faecal samples from 10 blood culture-positive children on admission. Therefore, this material can be considered a representative sample of children with urosepsis.

Previous studies have shown that E. coli attaches by means of $\mathrm{Gal} \alpha 1 \rightarrow 4 \mathrm{Gal} \beta$-containing receptors to colonic epithelial cells [12]. Also, it has been reported that children prone to UTIs carry P-fimbriate $E$. coli in their intestine more often than healthy controls [13]. Pfimbriate $E$. coli strains found in urine and faeces have been shown to be associated with bacteraemia in adults [14]. On the other hand, the clonal identity of the urinary and faecal strains has been reported in women with acute PN [15].

The present study showed for the first time that genetically identical isolates of E. coli causing PN and urosepsis in a child can also be found in the faeces of the same child. Therefore, the old theory - based on phenotypic markers of E. coli [16] - that the gut is the primary reservoir of these uropathogenic bacteria has

Table 1. Genetic clones of E. coli identified by PCR (papG classes I, II, III) and by PFGE(a-i) and O serotyping in 10 children with urosepsis

\begin{tabular}{|c|c|c|c|c|c|c|c|c|c|c|}
\hline \multirow[b]{2}{*}{ Origin of the isolate } & \multicolumn{10}{|c|}{ Characteristics of the isolates from child no. } \\
\hline & 1 & 2 & 3 & 4 & 5 & 6 & 7 & 8 & 9 & 10 \\
\hline Blood & IIc O6 & IId NT & IIIa O83 & IIe NT & IIIa O83 & IIf O6 & $\mathrm{IIg} \mathrm{O} 1$ & IIIi O6 & IIh $\mathrm{O} 1$ & $\mathrm{IIb} \mathrm{O} 1$ \\
\hline Urine & IIc O6 & IId NT & IIIa O83 & IIe NT & IIIa O83 & IIf O6 & IIg O1 & IIIi O6 & IIh O1 & IIb O1 \\
\hline Faeces & IIc O6 & IId NT & IIIa O83 & IIe NT & IIIa O83 & $\mathrm{II}^{*}$ & $\mathrm{~N} \dagger$ & IIIi O6 & $\mathrm{IIh} \mathrm{O} 1$ & $\mathrm{IIb} \mathrm{O} 1$ \\
\hline
\end{tabular}

NT, O antigen non-typable.

${ }^{*}$ Growth on the first streaking area pap $G$ class II positive; five separate colonies papG- negative.

$\dagger$ No pap $G$ found. 
been confirmed genetically. However, further studies on the pathogenesis and epidemiology of $E$. coli urosepsis are required before it is known why some individuals harbour pyelonephritogenic bacteria in their gut and how and for how long these bacteria colonise the gut and subsequently cause PN and occasionally sepsis.

We thank Liisa Immonen, Tarja Heiskanen, Joanna Koort, Aino Kyyhkynen and Ritva Taipalinen for excellent technical assistance and the staff of the participating hospitals: Aurora Hospital, Helsinki; Hospital for Children and Adolescents, University of Helsinki, Helsinki; Jorvi Hospital, Espoo; Päijät-Häme Central Hospital, Lahti and the Department of Pediatrics, Tampere University Hospital. This work was supported by the Foundation for Pediatric Research, Helsinki, Finland, the Research Funds of Helsinki University Central Hospital, TYH 8237 and the Finnish Kidney Foundation.

\section{References}

1. Grüneberg RN. Relationship of infecting urinary organism to the faecal flora in patients with symptomatic urinary infection. Lancet 1969; 2: 766-768.

2. Vosti KL, Goldberg LM, Monto AS, Rantz LA. Host-parasite interaction in patients with infections due to Escherichia coli. I. The serogrouping of $E$. coli from intestinal and extraintestinal sources. J Clin Invest 1964; 43: 2377-2385.

3. Källenius G, Möllby R, Svenson SB et al. Occurrence of Pfimbriated Escherichia coli in urinary tract infections. Lancet 1981; 2: 1369-1372.

4. Marklund B-I, Tennent JM, Garcia E et al. Horizontal gene transfer of the Escherichia coli pap and prs pili operons as a mechanism for the development of tissue-specific adhesive properties. Mol Microbiol 1992; 6: 2225-2242.

5. Jantunen ME, Siitonen A, Koskimies O et al. Predominance of class II papG allele of Escherichia coli in pyelonephritis in infants with normal urinary tract anatomy. J Infect Dis 2000; 181: $1822-1824$.
6. Murray PR, Baron EJ, Pfaller MA, Tenover FC, Yolken RH (eds) Manual of clinical microbiology, 6th edn. Washington, DC, ASM Press. 1995.

7. Kärkkäinen U-M, Kauppinen J, Ikäheimo R, Katila M-L, Siitonen A. Rapid and specific detection of three different $G$ adhesin classes of P-fimbriae in uropathogenic Escherichia coli by polymerase chain reaction. J Microbiol Methods 1998; 34: $23-30$.

8. Lukinmaa S, Schildt R, Rinttilä T, Siitonen A. Salmonella enteritidis phage types 1 and 4: pheno- and genotypic epidemiology of recent outbreaks in Finland. $J$ Clin Microbiol 1999; 37: 2176-2182.

9. Ørskov F, Ørskov I. Serotyping of Escherichia coli. In: Bergan $\mathrm{T}$ (ed) Methods in microbiology, vol 14. London, Academic Press. 1984: 43-112.

10. Majd M, Rushton HG, Jantausch B, Wiedermann BL. Relationship among vesicoureteral reflux, P-fimbriated Escherichia coli, and acute pyelonephritis in children with febrile urinary tract infection. J Pediatr 1991; 119: 578-585.

11. Hoberman A, Wald ER, Hickey RW et al. Oral versus initial intravenous therapy for urinary tract infections in young febrile children. Pediatrics 1999; 104: 79-86.

12. Wold AE, Thorssen M, Hull S, Svanborg-Eden C. Attachment of Escherichia coli via mannose- or Gal $\alpha 1 \rightarrow 4 \mathrm{Gal} \beta$-containing receptors to human colonic epithelial cells. Infect Immun 1988; 56: $2531-2537$.

13. Plos $\mathrm{K}$, Connell $\mathrm{H}$, Jodal $\mathrm{U}$ et al. Intestinal carriage of $\mathrm{P}$ fimbriated Escherichia coli and the susceptibility to urinary tract infection in young children. J Infect Dis 1995; 171: 625-631.

14. Brauner A, Leissner M, Wretlind B, Julander I, Svenson SB, Källenius G. Occurrence of P-fimbriated Escherichia coli in patients with bacteremia. Eur J Clin Microbiol 1985; 4: 566-569.

15. Mitsumori K, Terai Y, Yamamoto S, Yoshida O. Virulence characteristics and DNA fingerprints of Escherichia coli isolated from women with acute uncomplicated pyelonephritis. J Urol 1997; 158: 2329-2332.

16. Turck M, Petersdorf RG. The epidemiology of non-enteric Escherichia coli infections: prevalence of serological groups. $J$ Clin Invest 1962; 41: 1760-1765. 